\title{
IMPLEMENTASI BUDAYA LITERASI TERHADAP PENINGKATAN HASIL BELAJAR BIOLOGI SISWA KELAS X SMA NEGERI 4 JAYAPURA
}

\author{
Joko Waluyo $^{1)}$ dan Tiurlina Siregar ${ }^{2)}$ \\ 1) Mahasiswa Program Studi Magister Pendidikan IPA Universitas Cenderawasih \\ 2) Dosen Program Studi Magister Pendidikan IPA Universitas Cenderawasih
}

\begin{abstract}
The purpose of the study was to determine the implementation of literacy culture to increase learning outcomes in the material of the scope of biology of class X SMA Negeri 4 Jayapura.

The method in this study is furpossive sampling method and data collection techniques that will be used in the form of a questionnaire (questionnaire), namely data collection techniques carried out by giving a set of questions or written statements to respondents.

The results of this study are partially literacy culture does not have a significant effect on learning outcomes of the material scope of biology because based on the results of simple regression test obtained $t$ count $<t$ table $(0.075<1.960)$ or significant $t>5 \%(0.940>0.05)$ with regression equation $\mathrm{Y}=72,958+0.007 \mathrm{X} 3$ with a contribution or relative contribution of $0.00 \%$. There is an increase in the learning outcomes of the biological scope of class X students of SMA Negeri 4 Jayapura, where the average $n$-Gain test is obtained at 0.52 in the medium category.
\end{abstract}

Keywords: Implementation, Culture, Literacy, Biology.

\begin{abstract}
Abstrak. Tujuan penelitian adalah untuk mengetahui implementasi budaya literasi terhadap peningkatan hasil belajar pada materi ruang lingkup biologi siswa kelas X SMA Negeri 4 Jayapura.

Metode dalam penelitian ini adalah metode furpossive sampling dan teknik pengumpulan data yang akan digunakan berupa kuesioner (angket), yaitu teknik pengumpulan data yang dilakukan dengan cara memberi seperangkat pertanyaan atau pernyataan tertulis kepada responden.

Hasil penelitian ini adalah secara parsial budaya literasi tidak berpengaruh signifikan terhadap hasil belajar materi ruang lingkup biologi karena berdasarkan hasil uji regresi sederhana diperoleh $\mathrm{t}_{\text {hitung }}<\mathrm{t}_{\text {tabel }}(0,075<1,960)$ atau signifikan $\mathrm{t}>5 \% \quad(0,940>0,05)$ dengan persamaan regresi $\mathrm{Y}=$ $72,958+0,007 \mathrm{X}_{3}$ dengan sumbangan atau kontribusi relatif sebesar $0,00 \%$. Terdapat peningkatan hasil belajar materi ruang lingkup biologi siswa kelas X SMA Negeri 4 Jayapura, dimana dari uji $\mathrm{n}$-Gain rata-rata diperoleh sebesar 0,52 dengan kategori sedang.
\end{abstract}

Kata Kunci : Implementasi,Budaya,Literasi, Biologi. 


\section{PENDAHULUAN}

Siswa Sekolah Menengah Atas (SMA) mempunyai potensi dan kompetensi untuk bersaing dengan siswa dari negara yang lebih maju yang dinilai mampu dalam bidang matematika, sains, dan membaca.

Berdasarkan hasil kajian dan pengalaman empiris diketahui bahwa membaca merupakan salah satu rahasia sukses siswa dari negara maju tersebut. Masalahnya, kebiasaan membaca siswa SMA di Indonesia pada umumnya dan di Papua pada khususnya belum sepenuhnya tumbuh menjadi budaya. Oleh karena itu, kebiasaan membaca harus ditumbuh kembangkan di sekolah sebagai bagian dari pendidikan di SMA. Dalam rangka membudayakan kebiasaan membaca, Direktorat Pembinaan SMA memprogramkan pembinaan peningkatan minat membaca peserta didik SMA melalui gerakan literasi sekolah. Pada program tersebut, sekolah bersama dengan pemangku kepentingan lainnya memfasilitasi dan menggerakkan budaya membaca peserta didik.

Pada Tahun 2015 Kementerian Pendidikan dan Kebudayaan Indonesia mengeluarkan Peraturan Menteri No 23 Tahun 2015. Peraturan Menteri tersebut berisi tentang penumbuhan budi pekerti yang di dalamnya mencakup Gerakan Literasi Sekolah (GLS) dengan mewajibkan peserta didik membaca buku non pelajaran selama 10-15 menit sebelum pembelajaran dimulai. GLS bertujuan menumbuhkan budaya membaca dan menulis (literasi) pada warga sekolah, baik kepala sekolah, siswa, dan guru yang berujung pada kemampuan mamahami informasi secara analitis, kritis, dan reflektif. GLS juga bertujuan menciptakan lingkungan sekolah menjadi lingkungan pembelajar sepanjang hayat dengan membudayakan aktivitas membaca yang tidak sekedar membaca dan menulis yang tidak sekedar menulis. Konsep Gerakan Literasi Sekolah (GLS) yang kelihatannya mudah diterapkan, ternyata tidak mudah dalam pengaplikasiannya di sekolah. Hal tersebut dikarenakan, setiap sekolah tidak memilki kemampuan yang sama dalam mengakomodasi penciptaan lingkungan sekolah yang literasi.

Menurut Permendikbud Nomor 23 Tahun 2016 tentang penilaian hasil belajar oleh pendidik dan satuan pendidikan pada pendidikan dasar dan pendidikan menengah. Pasal 3 menyatakan bahwa "penilaian hasil belajar siswa pada pendidikan dasar dan pendidikan menengah meliputi aspek sikap, pengetahuan, dan keterampilan. Penilaian dilakukan oleh pendidik bertujuan untuk memantau dan mengevaluasi proses, kemajuan belajar, dan perbaikan hasil belajar peserta didik secara berkesinambungan dan penilaian hasil belajar oleh satuan pendidikan bertujuan untuk menilai pencapaian Standar Kompetensi Lulusan untuk semua mata pelajaran. Selanjutnya menurut 
Permendikbud Nomor 24 Tahun 2016 bahwa mata pelajaran Biologi di SMA/MA merupakan kelanjutan IPA di SMP/MTs yang menekankan pada fenomena alam dan penerapannya yang meliputi sejumlah aspek. Aspek pertama meliputi hakikat biologi, keanekaragaman hayati dan pengelompokan makhluk hidup, hubungan antar komponen ekosistem, perubahan materi dan energi, peranan manusia dalam keseimbangan ekosistem. Aspek kedua meliputi organisasi seluler, struktur jaringan, struktur dan fungsi organ tumbuhan, hewan dan manusia serta penerapannya dalam konteks sains, lingkungan, teknologi dan masyarakat. Aspek ketiga meliputi proses yang terjadi pada tumbuhan, proses metabolisme, hereditas, evolusi, bioteknologi dan implikasinya pada sains, lingkungan, teknologi dan masyarakat. Penilaian hasil belajar biologi harus memperhatikan karakteristik ilmu biologi sebagai sikap, proses dan produk. Selama ini ada kecenderungan sebagian guru biologi kurang memperhatikan karakteristik ilmu biologi dalam pembelajaran dan hasil belajar biologi. Dalam pembelajaran dan penilaian hasil belajar biologi tentunya tidak terlepas dari standar kualifikasi akademik dan kompetensi guru diantaranya adalah kompetensi pedagogik, kompetensi kepribadian, kompetensi profesional dan kompetensi sosial seperti menyelenggarakan perencanaan pembelajaran, melaksanakan pembelajaran, melakukan penilaian proses pembelajaran dan penilaian hasil pembelajaran dengan menumbuhkan pembiasaan karakter dalam membuat perencanaan dan pelaksanaan pembelajaran, serta menumbuhkan budaya literasi dan penilaian hasil pembelajaran. Penilaian hasil belajar biologi harus memperhatikan karakteristik ilmu biologi sebagai sikap, proses dan produk. Selama ini ada kecenderungan sebagian guru biologi kurang memperhatikan karakteristik ilmu biologi dalam pembelajaran dan hasil belajar biologi. Dalam pembelajaran dan penilaian hasil belajar biologi tentunya tidak terlepas dari standar kualifikasi akademik dan kompetensi guru diantaranya adalah kompetensi pedagogik, kompetensi kepribadian, kompetensi profesional dan kompetensi sosial seperti menyelenggarakan perencanaan pembelajaran, melaksanakan pembelajaran, melakukan penilaian proses pembelajaran dan penilaian hasil pembelajaran dengan menumbuhkan pembiasaan karakter dalam membuat perencanaan dan pelaksanaan pembelajaran, serta menumbuhkan budaya literasi dan penilaian hasil pembelajaran. Dalam implementasi kurikulum 2013 budaya literasi pada materi ruang lingkup biologi siswa kelas $\mathrm{X}$ di SMA Negeri 4 Jayapura perlu dikaji lebih lanjut. Perlunya dilakukan identifikasi dan analisis terhadap ketercapaian hasil belajar siswa sehingga dapat memberikan gambaran kekuatan dan kelemahan kompetensi guru, siswa dan sekolah. Oleh karena itu penulis lebih memfokuskan kajian " Implementasi Budaya Literasi terhadap Peningkatan Hasil Belajar Biologi Siswa Kelas X SMA Negeri 4 Jayapura. 


\section{METODOLOGI PENELITIAN}

Metode dalam penelitian ini adalah metode furpossive sampling dan teknik pengumpulan data yang akan digunakan berupa kuesioner (angket), yaitu teknik pengumpulan data yang dilakukan dengan cara memberi seperangkat pertanyaan atau pernyataan tertulis kepada responden untuk dijawabnya (Sugiyono, 2016). Selain dengan teknik tersebut, juga dilihat dari hasil belajar siswa. Angket digunakan untuk mengetahui pendapat dari responden tentang implementasi budaya literasi sedangkan hasil belajar menggunakan tes kognitif. Penelitian yang dilaksanakan di SMA Negeri 4 Jayapura menggunakan instrumen berupa seperangkat kuesioner (daftar pertanyaan atau pernyataan) berbentuk angket berstruktur, tes hasil belajar dalam bentuk obyektif atau pilihan ganda.

Pembuatan angket dalam penelitian ini menggunakan skala Likert. Skala Likert digunakan untuk mengukur sikap, pendapat, dan persepsi seseorang atau sekelompok orang tentang fenomena sosial (Sugiyono, 2016). Responden diminta untuk memilih salah satu jawaban yang sesuai dengan karakteristik dirinya dengan cara memberi tanda silang (X) atau tanda cheklist $(\sqrt{ })$. Jawaban setiap item instrumen yang menggunakan skala Likert mempunyai gradasi dari sangat positif sampai sangat negatif, yang dapat berupa kata-kata (Tabel 1) sebgai berikut :

Tabel .1. Kisi-kisi angket budaya literasi

\begin{tabular}{|c|l|l|l|}
\hline No. & \multicolumn{1}{|c|}{$\begin{array}{c}\text { Aspek yang } \\
\text { diteliti }\end{array}$} & \multicolumn{1}{|c|}{ Indikator } & \multicolumn{1}{c|}{$\begin{array}{c}\text { Nomor } \\
\text { Pertanyaan }\end{array}$} \\
\hline 1. & Pembiasaan & Rasa cinta membaca & $1,2,9,10,14$ \\
\hline 2. & $\begin{array}{l}\text { Kemampuan } \\
\text { membuat } \\
\text { ringkasan isi } \\
\text { bacaan }\end{array}$ & Memahami bacaan & $11,18,19,21,24$, \\
\hline 3. & $\begin{array}{l}\text { Aplikasi dalam } \\
\text { kegiatan belajar }\end{array}$ & $\begin{array}{l}\text { Rasa percaya diri sebagai } \\
\text { pembaca }\end{array}$ & $15,16,25$, \\
\hline 4. & $\begin{array}{l}\text { Ketersediaan } \\
\text { sumber bacaan }\end{array}$ & $\begin{array}{l}\text { Mengembangkan sumber } \\
\text { bacaan }\end{array}$ & $\begin{array}{l}3,4,5,6,7,8,12,2 \\
0,22,23,27\end{array}$ \\
\hline
\end{tabular}

Tes adalah serangkaian pertanyaan atau pernyataan latihan yang digunakan untuk mengukur keterampilan, pengetahuan, inteligensi, bakat yang dimiliki oleh individu atau kelompok (Riduwan,2010). Tes penelitian ini menggunakan tes hasil belajar pada ranah kognitif. Tes yang diberikan berupa tes obyektif dan uraian yang terdiri dari 20 soal pilihan ganda. Setelah pembelajaran selesai kemudian diberikan tes untuk mengetahui hasil belajar siswa. Kisikisi soal ditunjukkan pada Tabel 2. Berikut 
Tabel 2. Kisi-kisi soal

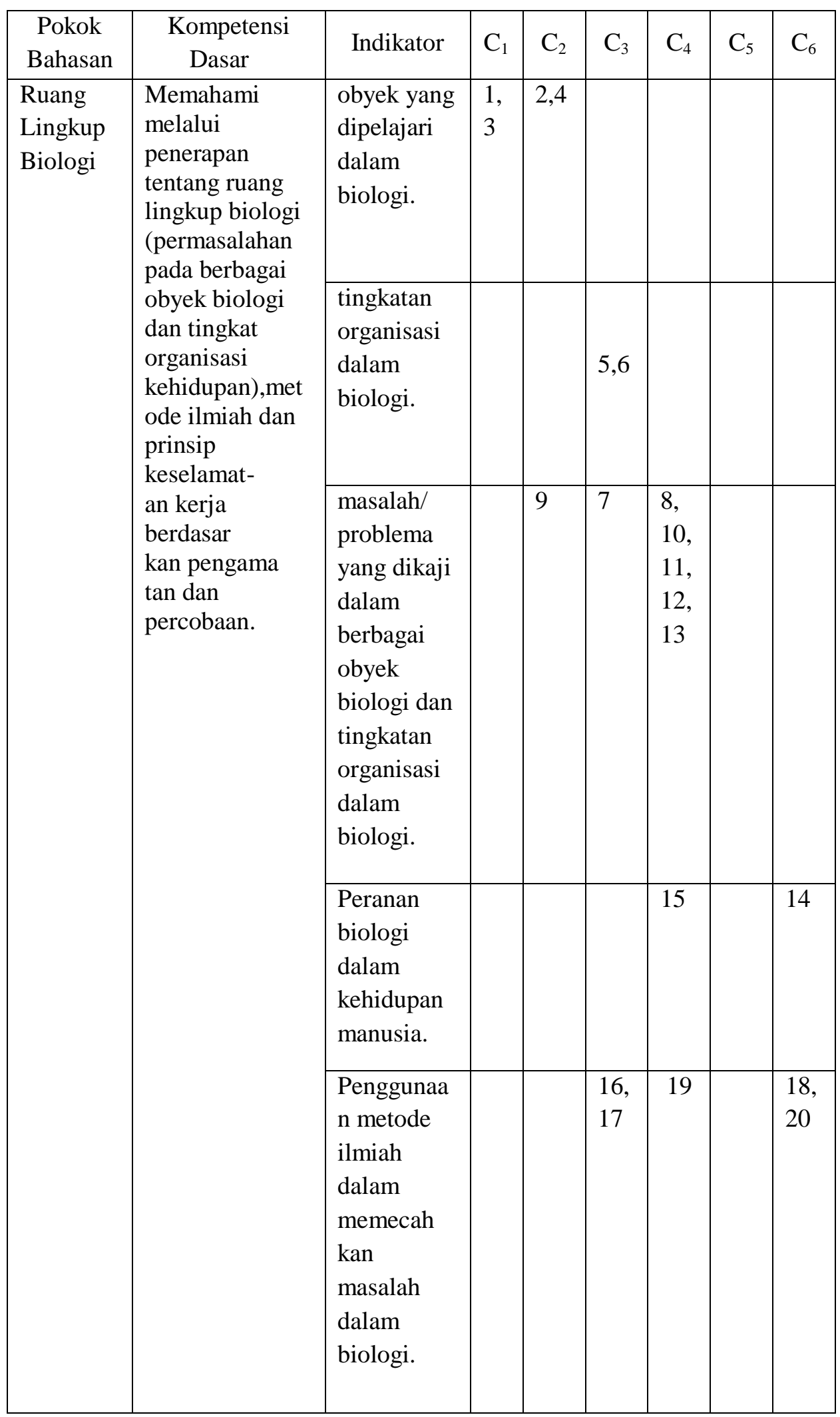


Nilai hasil belajar menggunakan standar Kriteria Ketuntasan Minimal (KKM) untuk materi ruang lingkup biologi yaitu 60 . Penentuan nilai KKM berdasarkan ketentuan dalam penyusunan yaitu dengan

Tabel 3. Pemberian skor pada penilaian hasil belajar

\begin{tabular}{|c|c|l|c|}
\hline No. & Rentang Nilai & \multicolumn{1}{|c|}{ Skala Likert } & Predikat \\
\hline 1. & $86-100$ & Amat Baik & A \\
\hline 2. & $73-85$ & Baik & B \\
\hline 3. & $60-72$ & Cukup & C \\
\hline 4. & $<60$ & Kurang & D \\
\hline
\end{tabular}

\section{Uji Validitas dan Realibilitas}

\section{Instrumen}

\section{Uji Validitas}

Validitas adalah suatu ukuran yang menunjukkan tingkat kevalidan atau kesahihan suatu instrumen tes. Sebuah tes dikatakan valid apabila tes tersebut dapat tepat mengukur apa yang hendak diukur (Arikunto, 2012:80). Untuk menguji validitas instrumen penelitian menggunakan rumus korelasi pearson product moment (r) (Riduwan, 2010) yaitu:

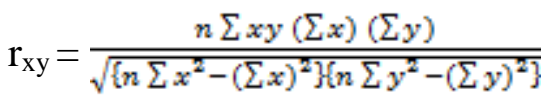

Dimana :

$$
\mathrm{r}_{\mathrm{xy}}=\text { Koefisien korelasi }
$$

antara variabel $\mathrm{X}$ dan $\mathrm{Y}$

$$
\sum_{\mathrm{x}}=\text { jumlah seluruh skor }
$$

item mempertimbangkan komponen intake, kompleksitas, dan daya dukung. Berdasarkan KKM tersebut dibuatlah skala Likert (Tabel 3) sebagai berikut 
instrumen tersebut sudah baik (Arikunto, 2012). Jika dihubungkan dengan validitas maka dikatakan bahwa instrumen yang reliabel belum tentu valid tetapi reliabilitas instrumen merupakan syarat untuk pengujian validitas instrumen (Sugiyono, 2016). Untuk mengetahui reliabilitas instrumen harus menggunakan rumus Spearman Brown. Riduwan (2010) yaitu :

$\mathrm{r}_{\mathrm{ii}}=\frac{2 r b}{1+r b}$

$\mathrm{r}_{\mathrm{ii}}=$ koefisien reliabilitas seluruh item

$\mathrm{rb}=$ korelasi product momen pembelajaran awal - akhir

$\mathrm{r}_{\mathrm{b}}=\frac{n \sum x y\left(\sum x\right)\left(\sum y\right)}{\sqrt{\left.\left[n \sum x^{2}-\left(\sum x\right)^{2}\right\} n \sum y^{2}-\left(\sum y\right)^{2}\right]}}$

Distribusi ( $\left.\mathrm{r}_{\text {tabel }}\right)$ untuk $\alpha=0,05$ dan derajat kebebasan $(\mathrm{dk}=\mathrm{n}-2)$

Kaidah keputusan :

Jika $r_{\text {ii }}>\quad r_{\text {tabel }}$ berarti reliabel, sebaliknya

Jika $r_{\text {ii }}<t_{\text {tabel }}$ berarti tidak reliabel

\section{Teknik Analisis Data}

Analisis korelasi yang digunakan dalam penelitian ini adalah korelasi Product Momen (r). Rumus yang digunakan korelasi Pearson Product Moment (Riduwan, 2010).

Langkah-langkah dalam mencari korelasi Pearson Product Moment adalah :

a. Membuat Ha dan Ho dalam bentuk kalimat.

b. Membuat Ha dan Ho model statistik,

c. Membuat tabel penolong untuk menghitung korelasi. d. Mencari $r_{\text {hitung }}$ dengan cara memasukkan angka statistik dari tabel penolong dengan rumus :

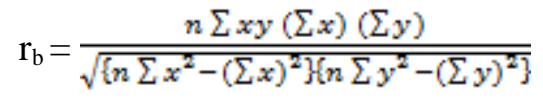

e. Mencari besar kecilnya sumbangan variabel $\mathrm{x}$ dengan variabel $\mathrm{y}$ dapat ditentukan dengan rumus koefisien determinasi.

f. Menguji signifikan dengan menggunakan rumus $\mathrm{t}_{\text {hitung, }}$ yaitu:

$$
\mathrm{t}_{\text {hitung }}=\frac{r \sqrt{n-2}}{1-x^{2}}
$$

\section{HASIL DAN PEMBAHASAN}

\section{Uji Validitas Instrumen}

Valid tidaknya suatu item instrumen dapat diketahui dengan cara membandingkan indeks korelasi product moment (Pearson Correlation) dengan kritis.Bila korelasi tiap faktor tersebut $r_{\text {hitung }}$ memiliki nilai lebih besar dari $r_{\text {tabel }}$, maka faktor tersebut merupakan construct yang kuat. Bila harga korelasi $r_{\text {hitung }}$ lebih kecil

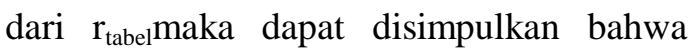
butir instrumen tersebut tidak valid.

Analisis validitas terhadap instrumen budaya literasi bahwa butir pertanyaan nomor 3, 8, 16, dan 26 dari instrumen penelitian tidak valid karena koefisien korelasinya dibawah $\mathrm{r}$ kritis $(0,266)$ sedangkan yang lainnya dinyatakan valid karena koefisien korelasinya di atas $r$ kritis $(0,266)$. Korelasi tertinggi memiliki koefisien 0,618 dan terendah 0,096. Dengan demikian, dari 33 butir insrumen budaya literasi yang 
dapat digunakan untuk pengukuran dalam analisis regresi ada 23 butir instrumen.

\section{Reliability Statistics menginformasikan} bahwa nilai Alpha Cronbach untuk item prestasi belajar sebesar 0,747. Kriteria menyebutkan, jika nilai korelasi sama atau lebih besar dari 0,600, maka butir-butir item tersebut reliabel. Informasi Cronbach's
Alphamenunjukkan bahwa instrumen budaya literasi mempunyai nilai > 0,600. Dengan demikian, maka instrumen budaya literasi reliabel.

Uji korelasi data variabel budaya literasi pada Tabel 4. diperoleh hasil sebagai berikut

Tabel 4. Hasil Uji Korelasi Budaya Literasi

\begin{tabular}{|l|l|l|l|}
\hline \multicolumn{2}{|l|}{ Uji Korelasi } & Budaya Literasi & Hasil Belajar \\
\hline Budaya & Pearson Correlation & 1 & 0,005 \\
& Siterasi & & 0,940 \\
& & 270 & 270 \\
\hline Hasil & Pearson Correlation & 0,005 & 1 \\
Belajar & Sig, (2-tailed) N & 0,940 & \\
& & 270 & 270 \\
\hline
\end{tabular}

Hasil analisis pada Tabel 4 . diperoleh koefisien korelasi 0,005 dengan $p$ value 0,940. Untuk menentukan koefisien korelasi tersebut signifikan atau tidak dapat dibandingkan dengan $r_{\text {tabel. }}$ Jikar hitung $_{\text {lebih }}$ kecil dari $\mathrm{r}_{\text {tabel }}$ koefisien korelasi dinyatakan tidak signifikan. Dengan jumlah data sebanyak 270, didapat $r_{\text {tabel }}$ pada sebesar
0,005. Hal ini menunjukkan bahwa $r_{\text {hitung- }}$ lebih kecil dari $\mathrm{r}_{\text {tabel }}(0,005<0,113)$. Dengan demikian dapat disimpulkan bahwa koefisien korelasi sebesar 0,005 adalah tidak signifikan.

Uji Regresi Linier Sederhana. Hasil Perhitungan Uji-t Budaya Literasi ditunjukkan pada Tabel 5.

Tabel 5.Hasil Perhitungan Uji-t Budaya Literasi

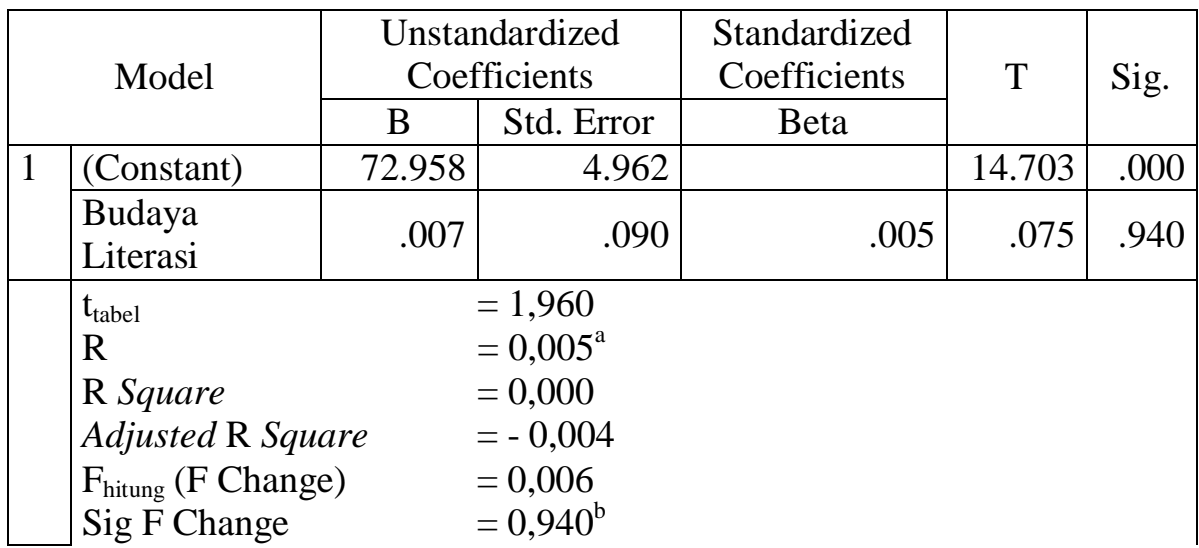

Nilai $t_{\text {hitung }}$ dalam penelitian ini pada Tabel signifikansi sebesar 0,940 lebih besar dari $\alpha$ 4.6 adalah sebesar 0,075 dengan tingkat $=0,05$. Karena $t_{\text {hitung }}<t_{\text {tabel }}(0,075<1,960)$ 
atau signifikan $\mathrm{t}<5 \%(0,940>0,05)$, maka secara parsial variabel budaya literasi $\left(\mathrm{X}_{3}\right)$ berpengaruh tidaksignifikan terhadap variabel hasil belajar (Y).Hal ini menunjukkan bahwa terjadi penolakan $\mathrm{H}_{\mathrm{a}}$ dan penerimaan $\mathrm{H}_{0}$ yang berarti variabel budaya literasi $\left(\mathrm{X}_{3}\right)$ berpengaruh tidak signifikan terhadap variabel hasil belajar (Y). Persamaan regresi sederhana dari budaya literasi dapat dituliskan sebagai berikut:

$\mathrm{Y}=\mathrm{a}+\mathrm{bX}_{3}$ maka persamaannya adalah $\mathrm{Y}=$ $72,958+0,007 \mathrm{X}_{3}$

1) Persamaan di atas mempunyai arti bahwa jika budaya literasi naik satu satuan, maka hasil belajar (Y) akan naik sebesar 0,005 satuan dengan anggapan variabel yang lain konstan.
2) Nilai $R$ sebesar $0,005^{\mathrm{a}}$ berarti bahwa hubungan antara variabel bebas budaya literasi terhadap variabel terikat yaitu hasil belajar termasuk kategori sangat rendah

3) Nilai determinasi (R Square) sebesar 0,000 artinya bahwa variasi berubahnya hasil belajar tidak dipengaruhi oleh budaya literasi sebesar $0,000 \%$.

\section{Hasil Perhitungan n-Gain}

Hasil penelitian ini untuk mengukur adanya selisih antara nilai postest dan pretest setelah pembelajaran materi ruang lingkup biologi dilakukan uji dengan menghitung nGain siswa kelas X SMA Negeri 4 Jayapura sebagaimana terdapat pada Tabel 6 sebagai berikut:

Tabel 6 . Hasil Perhitungan n-Gain Peserta Didik Kelas X SMA Negeri 4 Kota Jayapura.

\begin{tabular}{|c|c|c|c|c|c|}
\hline No & Peserta Didik (Kode) & Pre Test & $\begin{array}{c}\text { Post } \\
\text { Test }\end{array}$ & n-Gain & $\begin{array}{c}\text { Kategori Penguasaan } \\
\text { Konsep }\end{array}$ \\
\hline 1 & A & 50,00 & 75,00 & 0,50 & Sedang \\
\hline 2 & B & 31,25 & 87,50 & 0,82 & Tinggi \\
\hline 3 & C & 37,50 & 62,50 & 0,40 & Sedang \\
\hline 4 & D & 43,75 & 87,50 & 0,78 & Tinggi \\
\hline 5 & E & 50,00 & 75,00 & 0,50 & Sedang \\
\hline 6 & F & 31,25 & 93,75 & 0,91 & Tinggi \\
\hline 7 & G & 50,00 & 75,00 & 0,50 & Sedang \\
\hline 8 & H & 56,25 & 93,75 & 0,86 & Tinggi \\
\hline 9 & I & 43,75 & 50,00 & 0,11 & Rendah \\
\hline 10 & J & 50,00 & 75,00 & 0,50 & Sedang \\
\hline 11 & K & 31,25 & 87,50 & 0,82 & Tinggi \\
\hline 12 & L & 50,00 & 62,50 & 0,25 & Rendah \\
\hline 13 & M & 31,25 & 62,50 & 0,45 & Sedang \\
\hline 14 & N & 12,50 & 75,00 & 0,71 & Tinggi \\
\hline 15 & O & 50,00 & 93,75 & 0,88 & Tinggi \\
\hline 16 & P & 31,25 & 81,25 & 0,73 & Tinggi \\
\hline 17 & Q & 31,25 & 56,25 & 0,36 & Sedang \\
\hline 18 & R & 50,00 & 75,00 & 0,50 & Sedang \\
\hline 19 & S & 31,25 & 68,75 & 0,55 & Sedang \\
\hline 20 & T & 43,75 & 75,00 & 0,56 & Sedang \\
\hline 21 & U & 43,75 & 68,75 & 0,44 & Sedang \\
\hline 22 & V & 43,75 & 75,00 & 0,56 & Sedang \\
\hline 23 & W & 50,00 & 87,50 & 0,75 & Tinggi \\
\hline
\end{tabular}




\begin{tabular}{|c|c|c|c|c|c|}
\hline No & Peserta Didik (Kode) & Pre Test & $\begin{array}{l}\text { Post } \\
\text { Test }\end{array}$ & n-Gain & $\begin{array}{c}\text { Kategori Penguasaan } \\
\text { Konsep }\end{array}$ \\
\hline 24 & $\mathrm{X}$ & 31,25 & 87,50 & 0,82 & Tinggi \\
\hline 25 & $\mathrm{Y}$ & 50,00 & 68,75 & 0,38 & Sedang \\
\hline 26 & $\mathrm{Z}$ & 31,25 & 81,25 & 0,73 & Tinggi \\
\hline 27 & AA & 50,00 & 93,75 & 0,88 & Tinggi \\
\hline 28 & BB & 43,75 & 62,50 & 0,33 & Sedang \\
\hline 29 & $\mathrm{CC}$ & 50,00 & 75,00 & 0,50 & Sedang \\
\hline 30 & DD & 31,25 & 87,50 & 0,82 & Tinggi \\
\hline 31 & $\mathrm{EE}$ & 50,00 & 62,50 & 0,25 & Rendah \\
\hline 32 & FF & 56,25 & 62,50 & 0,14 & Rendah \\
\hline 33 & GG & 56,25 & 75,00 & 0,43 & Sedang \\
\hline 34 & $\mathrm{HH}$ & 31,25 & 93,75 & 0,91 & Tinggi \\
\hline 35 & II & 56,25 & 87,50 & 0,71 & Tinggi \\
\hline 36 & JJ & 43,75 & 18,75 & $-0,44$ & Rendah \\
\hline 37 & KK & 43,75 & 62,50 & 0,33 & Sedang \\
\hline 38 & LL & 50,00 & 68,75 & 0,38 & Sedang \\
\hline 39 & MM & 37,50 & 75,00 & 0,60 & Sedang \\
\hline 40 & $\mathrm{NN}$ & 43,75 & 68,75 & 0,44 & Sedang \\
\hline 41 & $\mathrm{OO}$ & 50,00 & 50,00 & 0,00 & Rendah \\
\hline 42 & $\mathrm{PP}$ & 56,25 & 87,50 & 0,71 & Tinggi \\
\hline 43 & QQ & 37,50 & 87,50 & 0,80 & Tinggi \\
\hline 44 & $\mathrm{RR}$ & 12,50 & 68,75 & 0,64 & Sedang \\
\hline 45 & SS & 37,50 & 75,00 & 0,60 & Sedang \\
\hline 46 & TT & 43,75 & 93,75 & 0,89 & Tinggi \\
\hline 47 & UU & 50,00 & 81,25 & 0,63 & Sedang \\
\hline 48 & VV & 56,25 & 68,75 & 0,29 & Rendah \\
\hline 49 & WW & 68,75 & 75,00 & 0,20 & Rendah \\
\hline 50 & XX & 12,50 & 87,50 & 0,86 & Tinggi \\
\hline 51 & YY & 25,00 & 75,00 & 0,67 & Sedang \\
\hline 52 & $\mathrm{ZZ}$ & 31,25 & 81,25 & 0,73 & Tinggi \\
\hline 53 & AAA & 18,75 & 87,50 & 0,85 & Tinggi \\
\hline 54 & BBB & 43,75 & 93,75 & 0,89 & Tinggi \\
\hline 55 & $\mathrm{CCC}$ & 43,75 & 81,25 & 0,67 & Sedang \\
\hline 56 & DDD & 18,75 & 56,25 & 0,46 & Sedang \\
\hline 57 & EEE & 37,50 & 62,50 & 0,40 & Sedang \\
\hline 58 & FFF & 43,75 & 75,00 & 0,56 & Sedang \\
\hline 59 & GGG & 50,00 & 68,75 & 0,38 & Sedang \\
\hline 60 & $\mathrm{HHH}$ & 56,25 & 50,00 & $-0,14$ & Rendah \\
\hline 61 & III & 37,50 & 56,25 & 0,30 & Sedang \\
\hline 62 & JJJ & 37,50 & 75,00 & 0,60 & Sedang \\
\hline 63 & KKK & 37,50 & 93,75 & 0,90 & Tinggi \\
\hline 64 & LLL & 43,75 & 87,50 & 0,78 & Tinggi \\
\hline 65 & MMM & 50,00 & 68,75 & 0,38 & Sedang \\
\hline 66 & NNN & 50,00 & 50,00 & 0,00 & Rendah \\
\hline 67 & $\mathrm{OOO}$ & 68,75 & 56,25 & $-0,40$ & Rendah \\
\hline \multirow[t]{3}{*}{68} & PPP & 25,00 & 68,75 & 0,58 & Sedang \\
\hline & Jumlah & 2843,75 & 5037,50 & 35,82 & \\
\hline & Rata-rata & 41,82 & 74,08 & 0,52 & Sedang \\
\hline
\end{tabular}

Hasil penilaian diperoleh jumlah nilai ratarata pretest sebesar 41,82, nilai rata-rata postest sebesar 74,08, dan jumlah skor maksimum 100. Hasil perhitungan nilai 
pretest dan nilai postest ada peningkatan sebesar 0,52. Dengan demikian bahwa peningkatan penguasaan konsep materi ruang lingkup biologi peserta didik kelas X SMA Negeri 4 Jayapura berada di atas 0,3 dan di bawah 0,7 yang berarti siswa memiliki penguasaan konsep kategori sedang.

\section{Pembahasan Penelitian}

Hasil uji parsial dapat dibuktikan bahwa variabel budaya literasi tidak berpengaruh signifikan terhadap hasil belajar peserta didik. Hal itu dapat diketahui melalui nilai $t_{\text {hitung }}$ sebesar 0,75 dengan tingkat signifikansi sebesar 0,940 lebih kecil dari $t_{\text {tabel }} \quad$ sebesar $1,960 \quad$ karena $\quad t_{\text {hitung }}<t_{\text {tabel }}$ $(0,75<1,960)$ atau signifikan $\mathrm{t}>5 \%$ $(0,940>0,05)$, maka secara parsial variabel budaya literasi $\left(\mathrm{X}_{3}\right)$ berpengaruh tidak signifikan terhadap variabel hasil belajar (Y).Hasil perhitungan ini menunjukkan bahwa terjadi penolakan $\mathrm{H}_{\mathrm{a}}$ dan penerimaan $\mathrm{H}_{0}$ yang berarti variabel budaya literasi $\left(\mathrm{X}_{3}\right)$ berpengaruhtidaksignifikanterhadap variabel hasil belajar (Y). Persamaan regresi sederhana $\mathrm{Y}=72,958+0,007 \mathrm{X}_{3}$ artinya bahwa jika budaya literasi naik satu satuan, maka hasil belajar (Y) akan naik sebesar 0,005 satuan dengan anggapan variabel yang lain konstan.

Hasil analisis korelasi antara budaya literasi diperoleh nilai koefisien korelasi $\mathrm{R}$ sebesar 0,005. Nilai ini menunjukkan bahwa keterkaitan antara budaya literasi terhadap hasil belajar sangat rendah. Dengan demikian, budaya literasiyang diterapkan kepada peserta didik sebelum pembelajaran memiliki korelasi sangat rendah terhadap hasil belajar bila dibandingkan dengan implementasi kurikulum dan penguatan pendidikan karakter peserta didik kelas $\mathrm{X}$ SMA Negeri 4 Jayapura.

Besarnya sumbangan atau kontribusi variabel budaya literasi terhadap hasil belajar materi ruang lingkup biologi dapat diketahui melalui nilai koefisien determinasi ( $R$ Square) sebesar 0,000. Hasil analisis tersebut menunjukkan bahwa $0,000 \%$ variasi perubahan hasil belajar ditentukan dengan pola fungsionalnya seperti ditunjukkan oleh persamaan regresi budaya literasi. Artinya budaya literasi yang diterapkan kepada siswa SMA Negeri se-Kota Jayapura sebelum proses belajar mengajar kurang lebih 0,000 $\%$ skor variabel akan mengikuti pola persamaan regresi $\mathrm{Y}=72.958+0,007 \mathrm{X}_{3}$.

Hasil penelitian menunjukkan adanya pengaruh yang tidak signifikan antara budaya literasi terhadap hasil belajar disebabkan budaya literasi yang dilaksanakan sebelum proses belajar mengajar peserta didik membaca buku non pelajaran. Hal ini yang membuat tidak adanya hubungan antara budaya literasi dengan hasil belajar materi ruang lingkup biologi peserta didik kelas X SMA Negeri 4 Jayapura. Nilai rata-rata pretest sebesar 41,82 , nilai rata-rata postest sebesar 74,08 , dan jumlah skor maksimum 100. Hasil perhitungan nilai pretest dan nilai postest ada peningkatan sebesar 0,52. Dengan demikian bahwa peningkatan penguasaan konsep materi ruang lingkup biologi peserta didik 
kelas X SMA Negeri 4 Jayapura berada di atas 0,3 dan di bawah 0,7 yang berarti siswa memiliki penguasaan konsep kategori sedang.

Tujuan Gerakan Literasi Sekolah (GLS) adalah agar peserta didik lebih melek literasi, berwawasan luas, berkarakter, dan berbudi pekerti. GLS ini merupakan program dari Kementerian Pendidikan dan Kebudayaan Republik Indonesia. Menurut Panduan Gerakan Literasi Sekolah (2016:2) "GLS merupakan sebuah upaya yang dilakukan secara menyeluruh untuk menjadikan sekolah sebagai organisasi pembelajaran yang warganya literat sepanjang hayat melalui pelibatan publik".

Hasil wawancara kepada siswa pada kegiatan $10-15$ menit membaca buku non pelajaran dalam hati maupun membacakan nyaring,yang dilaksanakan pada SMA Negeri 4 Jayapura masih terdapat keterbatasan. Hal ini dapat dilihat juga dari hasil angket pelaksanaan budaya literasi yang terlaksana baru mencapai 4,44\%disebabkan ; 1) Minimnya sarana membaca yang dimiliki sekolah; 2) Kurangnya motivasi membaca; 3) Rendahnya kemauan siswa mengembangkan gagasan; 4) Kurangnya sumber bacaan; 5) Kurang kondusifnya fasilitas perpustakaan di sekolah. Perpustakaan sekolah yang seharusnya merupakan salah satu penunjang untuk pelaksanaan program Gerakan Literasi Sekolah, belum berfungsi sebagai penyedia bahan bacaan dan sumber informasi bagi siswa.Perpustakaan belum mampu menjadi penyedia sarana literasi, yaitu sudut baca kelas, area baca, dan lingkungan kaya teks.
Budaya literasi yang diberlakukan di sekolah bukan mengarahkan siswa untuk meningkatkan hasil belajar, namun lebih mengarahkan pada pembiasaan siswa menumbuhkan minat membaca untuk meningkatkan keterampilan membaca. Hal ini seiring kebijakan pemerintah membudayakan kegiatan 10 - 15 menit membaca buku non pelajaran sebelum waktu belajar dimulai. Materi baca berisi tentang nilainilai budi pekerti, berupa kearifan lokal, nasional, dan global sesuai dengan jenjang pendidikan.

\section{Simpulan dan Saran}

Berdasarkan hasil penelitian yang telah dilakukan dapat disimpulkan sebagai berikut:

Secara parsial budaya literasi tidak berpengaruh signifikan terhadap hasil belajar materi ruang lingkup biologi karena berdasarkan hasil uji regresi sederhana diperoleh $\mathrm{t}_{\text {hitung }}<\mathrm{t}_{\text {tabel }}(0,075<1,960)$ atau signifikan $t>5 \% \quad(0,940>0,05)$ dengan persamaan regresi $\mathrm{Y}=72,958+0,007 \mathrm{X}_{3}$ dengan sumbangan atau kontribusi relatif sebesar $0,00 \%$.

Terdapat peningkatan hasil belajar materi ruang lingkup biologi siswa kelas X SMA Negeri 4 Jayapura, dimana dari uji n-Gain rata-rata diperoleh sebesar 0,52 dengan kategori sedang.

Saran

Budaya literasi hendaknya diarahkan pada membaca buku -buku yang terkait dengan mata pelajaran sehingga kebijakan 
yang diterapkan bukan hanya menumbuhkan minat membaca namun lebih pada untuk meningkatkan hasil belajar peserta didik.

\section{DAFTAR PUSTAKA}

Arikunto,2012. Prosedur Penelitian: Suatu Pendekatan Praktik. Jakarta: Rineke Cipta.

Peraturan Menteri Pendidikan dan Kebudayaan Republik Indonesia No 23 Tahun 2016 tentang Penilaian Hasil Belajar oleh Pendidik pada Pendidikan Dasar dan Pendidikan Menengah..

Peraturan Menteri Pendidikan dan Kebudayaan Republik Indonesia Nomor 23 Tahun 2015 tentang Penumbuhan Budi Pekerti.

$$
\begin{aligned}
& \text { Peraturan Menteri Pendidikan dan } \\
& \text { Kebudayaan Republik Indonesia } \\
& \text { Nomor } 23 \text { Tahun } 2016 \text { tentang } \\
& \text { Standar Penilaian Pendidikan.. }
\end{aligned}
$$

Riduwan.2010. Metode dan Teknik Menyusun Proposal Penelitian. Bandung: Alfabeta.

Sugiyono. 2016: Metode Penelitian Pendidikan, Pendekatan Kuantitatif, Kualitatif, dan R \& D. Bandung: Alfabeta.

Tabloid Jubi.com. 2017. Sekolah di Kota Jayapura Mulai Terapkan Kurikulum 2013, (online). (http://www.jubi.com) Diunduh tanggal $16 \quad$ September 2017 